\title{
Losing the Heritage - Falling out of Love with Cricket: Why Has This Happened to the British Afro-Caribbean Community?
}

\author{
Russell Holden \\ Zone Sport and Politics Consultancy, UK
}

Copyright $(2017$ by authors, all rights reserved. Authors agree that this article remains permanently open access under the terms of the Creative Commons Attribution License 4.0 International License

\begin{abstract}
Since the late 1990s, English and Welsh cricket has undergone substantial organisational and financial change, spurred on by the increase in one-day cricket, particularly the shortened Twenty 20 format, which is designed in part to introduce the game to a wider audience. In terms of playing personnel, one of the most dramatic developments has been the decline in numbers originating from the Afro-Caribbean community. One of the chief consequences of this has been the virtual lack of black cricketers representing England at a range of age levels. Chris Jordan's selection for the 2014 Test series against Sri Lanka doubled the number of Afro-Caribbean cricketers appearing for England in Test cricket this century. Whereas formerly, cricket was central to the lives of many in the Afro-Caribbean community, enthusiasm for the history and love of the game has withered. My article explores why it is that the Afro-Caribbean community no longer reveres cricket as it used to, and poses the question why, as a parent, one would make an active choice to dissuade or not expose one's children to cricket, a pastime that offers tremendous opportunity for both physical and social expression. Furthermore, in terms of evolving contemporary black identity and evidence of passive discrimination, this article considers whether cricket is being marginalised because it is deemed unappealing, insufficiently financially rewarding and just not sexy enough, or whether the lack of space in urban settings, class barriers and the cost of playing the game is simply too expensive for those outside the middle class, or those not fortunate enough to obtain an academic bursary or possess well established cricketing connections.
\end{abstract}

Keywords Diaspora, Hierarchy, Opportunity, Identity and Participation

\section{Introduction}

Whereas in former times, cricket was central to the lives of many in the British Afro-Caribbean community, enthusiasm for the history and love of the game has declined. This begs the question why is it that the community no longer reveres cricket as it once did? In this paper the chief objective is to explore this significant societal change through a consideration of the changing role and status of the game through an assessment of the place of cricket in an evolving contemporary Black British Afro-Caribbean identity. This development will be considered against the backdrop of cricket's reduced status in national life despite the 2005 Ashes victory, the improved performance of the England cricket team in all formats during the past decade, the small Afro-Caribbean player-pool available and the reality that sport shapes ideas of ethnic and racial identity. Throughout, it will be noted that the sport provides a vital source of social capital Burdsey [1].

Chris Jordan's England selection for the 2014 Sri Lanka Test Series was significant in that it doubled the number of Afro-Caribbean cricketers appearing for England in Test matches this century. However, a sharper response from the West Indies Cricket Board could easily have resulted in the Barbados-born-and-raised Jordan playing for the West Indies against England in the 2015 Test series. The England and Wales Cricket Board's fleetness of foot in this case in identifying talent intensifies the need to address the issue of why there is a lack of Afro-Caribbean youngsters entering the first-class game. According to Carl Greenidge [2], Former County professional and co-creator of the Grass Roots Cricket Academy, (a scheme designed to introduce cricket to disadvantaged London communities), even the Twenty 20 format "has not reached the Afro-Caribbean population for some odd reason, with the total shift in cultural taste having made cricket unappealing and just not sexy enough." Jordan's selection once again demonstrated that within the Home Nations the Caribbean community beyond the case of Michael Carberry were not able, for a variety of reason to produce a cricketer who had effectively learnt the game within the United Kingdom who has been 
deemed sufficiently skilled for Test cricket. This paper will seek to assess these reasons.

Michael Carberry's abrupt jettisoning by the England selectors following the 2012/13 Ashes Series (despite being England's second highest scoring batsman during the five match series), could well signify the end of an era, as he represents a period in British Caribbean history when cricket remained a pivotal element in the make-up of Afro-Caribbean identity in England and Wales. Although he did not have the practical West Indian schooling in cricket, his career overlapped with the likes of Phillip DeFreitas, Chris Lewis, Alex Tudor, Mark Alleyne, Adrian Rollins, Joey Benjamin and Ricky Anderson, significant contributors to their county clubs and, in the case of DeFreitas, Tudor, Lewis, Benjamin and Alleyne, to the England cause at Test or One-Day level. As English cricket has become more self-confident and successful since 2005, it has done so with only a minimal number of black players represented, in contrast to the emerging trend in the national side during the late 1980 s and early 1990 s.

Using a cultural studies perspective it will be argued throughout that sport simultaneously affects, and is affected by wider society, more especially its contextual relationships. The benefit of using this approach is that this methodology articulates the view that all social behaviour is in some form both enabled and constrained by economic, political, cultural and gendered power relations. In terms of British Afro-Caribbean cricket, this methodology helps to construct the economic and socio-political setting in which the sport has constantly been under challenge from its colonial heritage through to the present day. Furthermore, it helps to formulate an understanding of the degree to which cricket has, or has not been at the forefront of cultural assimilation within a multi-cultural society, or whether it remains scarred by a form of racism which few within the game choose to publicly acknowledge. Surprisingly as Williams notes, studies of race and ethnicity in sport, more especially cricket, remain scarce.

\subsection{Changing Cricketing Context}

As Malcolm [3] correctly points out, cricket's is distinguished by its paradoxical status as both the game of Empire yet at the same time the sport that most closely resonates with the notions of Englishness. For the Caribbean diaspora this presents a dilemma in so far as it challenges the continuing importance and relevance of the long established West Indian cricket heritage, with the need to adjust an evolving identity in which the sport continues to be deemed important and relevant to daily life and constantly evolving identities.

Ed Weetch [4] suggested in the Nightwatchman that at the heart of "The Carberry Question" namely, his selection and non-selection for England was the England and Wales Cricket Boards's EWCB) dismissive attitude towards the Afro-Caribbean community. "Elite layers are recruited from what seems to be an increasingly narrow social base." Although correct in arguing that the professional base has narrowed, with many in the sport guilty of failing to look beyond the traditional routes of entry into the first class game, (in particular private education and family connection) he and others continue to assume that Afro-Caribbean youngsters exist in substantial numbers ready to pursue professional cricketing careers. However, the essence of my argument concerns the wider issue of the degree to which the Afro-Caribbean community still love and respects cricket in the fashion it once did. As Mark Alleyne [5] noted, "The connection with cricket used to be contemporary, now it's a third and fourth generation, and each one is disconnecting a little more with the game, much to my dismay."

Consequently, this discussion will focus on the development and essence of the West Indian diasporic community, the challenges of immigration and racism that have confronted those of the Windrush and subsequent generations, as well as the role of the Afro-Caribbean community in nurturing and supporting cricket in the daily life of its members. The latter has been subject to the impact of the continuing decline in the numbers of West Indian cricket clubs, as well as the drop-off in the fortunes of the West Indies team. All of this serves to stiffen the task of encouraging the take-up of cricket by Afro-Caribbean boys and girls whose opportunities to play the sport are already limited by a lack of resources, in addition to the cost of playing the sport be it in formal education or through second chance opportunities offered by a range small-scale grass-roots organisations.

Equally, it is necessary to consider whether the community is culpable in failing to push its youngsters towards the game and to promote the sport within its own ranks. In seeking to establish whether this is the case, I acknowledge the alternative sporting opportunities open to young Afro-Caribbean males, as well as the impact of the decline of the West Indies as a major cricketing nation. Each of these factors makes recruitment into the game tougher for those working beyond the narrow orthodox structures of talent identification, coaching and mentoring. Furthermore, as Marqusee (1998) [6] and Weetch (2013) [7] suggest the Asian communities have been targeted more as a source of player recruitment (the EWCB 2014-2017 strategic plan makes no mention of Britain's black population) because of the continuing devotion and following of the game which has intensified in recent times within the South Asian communities as a consequence of their success combined with the growth of satellite television which has taken coverage into millions of households across the United Kingdom.

In tracing the emergence of four of the most successful of the current generation of Afro-Caribbean players, Tymal Mills (close personal friendship and county mentoring), Dominic Bell-Drummond (the beneficiary of a scholarship to Millfield School), Keith Barker (godson of former West Indies captain, Clive Lloyd), Chris Jordan (identified by the 
quintessentially English Bill Athey in his capacity as a talent scout for Dulwich College), it will be argued that though chance may have played a role in their development, the issue is far more deep-rooted and longstanding. In seeking to take on the mantle of Michael Carberry, each of the aforementioned players has received support from key individuals who have helped to smooth their path to advancement, a boon that many potential players lack.

\subsection{Diasporic Issues}

Throughout its history, Britain has absorbed a wide variety of peoples and has never insisted on some primal or essential national identity with which all must conform. Attempts to exclude incomers or certain ethnic groups from sharing national identity hinge greatly on their perceived threat. However, the influence of minority ethnic communities in Britain on cricket has been largely superficial, despite having adapted the traditional value system of the game. They have done little to legitimately challenge cricket's organisation and governance. This continues to be the case as these communities are under-represented as coaches, umpires, and key policy-makers.

This situation confirms as Spacklen [8] suggests that the current ideology of sport as individual freedom coupled with pure competition is scarred by the way in which both sport and sport histories foster myths of elitism and the exclusion of others. Modern sport continues to shift around the tension between those who seek to convey their passion for sport and those who use culture (incorporating sport) as a vehicle to control others as a soft means of social control Fletcher [9]. Within this reality, racism is evident as a controlling mechanism, which can result in limiting the involvement of minority ethnic communities in sport making them invisible and constituting a form of institutionalised racism. This is a reality that has impacted on cricket, though the lack of sustained sociological research, most notably of grass-roots cricket, has impacted on a fuller understanding of these issues beyond the assertion of passive discrimination. The work of Fletcher [10] has gone some way to redressing this gap; however, the emphasis of this valuable work has been on Asian cricket.

In most instances, any challenges have constituted individualised responses which have had impact only at the symbolic level. For instance, McDonald and Ugra [11] (1998) illustrate that white cricket clubs have the power to effect the continued exclusion of many ethnic minority cricketers. Similarly, Searle [12] (2001) argues that, despite its quality and considerable following, Black and Asian cricket is attributed little status within the hierarchy of English cricket often having to operate outside official structures of the game, with poor facilities and sparse funding. However, the pressure for change from the South Asian community will surely intensify with England having included four players of Asian origin in the side competing during the First Test Match in the series against India in autumn 2016. However,
Black and Asian cricket is still hampered by the fact that both communities lack the socio-political power to challenge and overcome dominant perceptions and power structures.

Cricket is critical to some diaspora communities and in the case of those that came on SS Windrush and subsequent maritime crossings, the game have played a number of roles. Cricket was critical as a leisure pursuit, as a meeting point via collective spectatorship, and for some, a source of employment. In the early 1960's the West Indies team took on the mantle of Caribbean togetherness as the West Indies political federation crumbled. At both grassroots and professional levels, cricket showed itself to be crucial to identity formation.

However, most important of all in the early years of immigration was the function cricket played in carving out a West Indian identity in Britain re-fashioning and sustaining the link established through the British Empire and he subsequent independent movement. Whereas during the period from 1963 until the mid 1990s the diaspora could speak to the nation through cricket, this is no longer possible as the key catalyst enabling this to occur, namely, the continuing strength of the West Indies side has evaporated. The weak West Indies eleven no longer engenders a deep sense of national pride. Now, despite the complexity of identity formation in relation to cricket, the game has become more than a cricket match for sections of the South Asian diasporic community in Britain, who have inherited much of the Afro-Caribbean vitality and desire to play and support the game in sizeable numbers as participants (all levels) and as supporters.

The attempted exclusion or assimilation of minority ethnic communities is thus best understood as a defensive reaction to situations of uncertainty and perceived crisis in the English game. This was best illustrated by the 1990 announcement from Norman Tebbit [13] of his "Cricket Test," namely the judging of assimilation into British society on the basis of which team is supported, and the stinging attack on non-British born cricketers by Robert Henderson [14] who claimed that players not born in the United Kingdom were not fully committed to the cause of England. Both instances enable understanding of why for many, even in the age of globalisation nostalgic visions of cricket and 'Englishness' continue to be relevant. As a result, any alternative forms of the game, or any other value systems are constructed as being subordinate because they lack authenticity and constitute part of the mythology of whiteness. This reflects a problem with cultural insularity within cricket generating a set of exclusionary barriers that have extended the history and reality of 'othering' within cricket. The reality being that it has remained difficult for some communities to try and even to want to break through into cricket's establishment and inner sanctum. Until the mid 1990's this was a particular problem within Yorkshire cricket which begun to change with the addition of Sachin Tendulkar and Richie Richardson to the County playing staff during the mid 1990's. 
Attacking the West Indian crowds with restrictions on the use of musical instruments, displaying of flags and banners and the amount of alcohol to be brought into the ground implied that supporters had to alter their behaviour and behave like the English. Cricket became a mechanism for the construction of levers of controls which ultimately reduced this collective sense of self, putting people off attending from the Afro-Caribbean community thus discouraging spectatorship of major sporting events, often a major display and manifestation of diaspora consciousness and unity. It also served to encourage more teams to operate outside the official structures, generating an element of segregation within the sport.

\subsubsection{Permanent Settlement}

The 1963 tour of England by the West Indies (a West Indian victory by three matches to one)) helped to make many in the Afro-Caribbean community more secure in their new surroundings, more confident about their heritage, and increasingly comfortable about their own sporting prowess. In this era, cricket played a vital role within the community, forging bonds amongst individuals previously scarred by inter-island rivalry, in addition to providing a safe environment in which West Indian heritage could be preserved and celebrated. The game offered a focus and helped to create an identity in an England that was still adjusting to the needs of an evolving post-colonial society. As in the Caribbean, cricket could still be perceived as a force encouraging liberation, yet as the West Indies became more integrated into national life, it began to struggle to play a key socio-political role and its significance as an agent for change lessened, reducing its appeal to those from the younger age groups who were being increasingly drawn to a range of other sports.

As Mike Phillips notes cricket, and West Indian cricket more especially, provided West Indian migrants with their most fundamental form of expression.

"There was only one way of expressing West Indian character and a Caribbean presence, and that was cricket. Because it came out of Britain in the first place it offered a sort of bridge into the English culture. We understood what it meant to be part of this society partly because we understood cricket." (Phillips [15])

Over time, this impacted on the strength and numbers of Caribbean cricket clubs both in and outside of London as this new generation made its mark. The 1960 s produced individuals that were both culturally Caribbean yet directly British through their engagement with football. Having being brought up in an environment where football was predominant, individuals did not naturally gravitate to the park or nearest piece of waste ground to play cricket, as was the case in the Caribbean. Preferences for England's national sport over the more traditional Caribbean-based sports signified more complex Afro-Caribbean and British ethnic identities. Cricket was increasingly perceived as the sport of the second generation's parents.
However, for Michael Carberry [16], who spoke both glowingly and touchingly about his parents and their devotion to cricket and the informal network of Caribbean fixtures that used to exist within Greater London, the situation was different. "Cricket was the first sport in the house," he said. "My family recognised I had a talent and I was fortunate to have two parents who were very much behind what I did. They bought kit and washed the kit and a lot of kids do not have that support."

Dominic Bell-Drummond's father played for Dorset in the Minor Counties Championship and retained strong links with Catford Cricket club and encouraged his son to play cricket from the age of three, thus planting the seeds of his ambition, whereas Alex Tudor the former Surrey and Essex fast bowler, has always maintained that his strong Barbadian roots and family obsession with cricket helped to launch his career. Yet, these are exceptional cases and contrast strongly with the chance encounter with cricket that alerted Tymal Mills [17] to his potential talent. "I played a little cricket at school, but nothing serious until the age of fourteen when I was persuaded by a good friend to give it a go." Once his talent was recognised by Essex, the role of the Academy Director became critical, "John Childs was very supportive, regularly coming to meet my Mum to discuss and explain my progress."

Although the second generation felt more comfortable supporting and representing England, many idolised the swagger and batsmanship of Richards and raw speed and skill of fast bowlers such as Roberts, Holding, Garner, Croft and Marshall. These figures symbolised role models to be copied and though it was difficult to break into the first-class game there remained a desire to emulate the feats of these cricketing stars. The gradual erosion by the cricket establishment of the carnival atmosphere generated by West Indian supporters at English international venues did not endear itself to the Afro-Caribbean community, whilst the rising prices charged at Test match venues also discouraged their attendance. The handover of the West Indies captaincy Viv by Richards to Richie Richardson, also marked the end of an era in which the imperative of political consciousness which characterised the team, slipped off the players agenda with it being deemed less important and relevant than previously. This non-political agenda was further strengthened when Brian Lara became captain as he prioritised the financial and commercial imperative within his style of leadership.

\subsection{Role of the Caribbean Community}

For all the criticism targeted at the EWCB for its lack of leaders strategic thinking on how to nurse a future generation of Afro-Caribbean youngsters, the responsibility for the enormous decline of players also has to rest with the community itself, as journalist Dean Wilson [18] has long maintained. In speaking to Alf Langley at the Lord's Cricket School, a deeper insight into this argument was offered. As 
the former chair of the Club Cricket Conference and the recently launched African-Caribbean Cricket Association, Langley [19] conveyed the gravity of the problem; "Cricket has to make itself more attractive and relevant. At the moment it is failing to do so." In this context, he is responding to those (himself included) who bemoan why so little cricket is played within the Afro-Caribbean community, particularly when the game offers so much in terms of life skills and social benefits. Although the potential pool of players compares unfavourably with the numbers of those of South Asian origin, the most perplexing concern is, he asserts, "Why, as a parent, would one make an active choice to dissuade or not expose your kids to cricket?" The only rational explanation can be that of cost. Furthermore, as Mark Alleyne [20] points out "In seeking to secure a county academy place the parental role is significant, and the support required is often not available as parents may lack the confidence to push their child or alternatively are complacent that their child's ability will secure a contract." This lack of encouragement and subsequent sport has resulted in potential talent slipping away as easily influenced adolescents have been drawn to other sports and in some instances, crime.

The declining appeal of cricket to young Afro-Caribbean males is not simply attributable to the game appearing tedious and demanding too much time as even the Twenty 20 format has made little difference. As Lawrence Prittipaul [21], co-founder of Cage Cricket, an initiative that develops the game in deprived inner-city communities, suggests, "the lack of space and money" also disadvantage those seeking to play the sport. In recounting his limited opportunities whilst growing up in Portsmouth, Prittipaul maintains that cricket should not exclude anyone from having the chance to play the game, though the increasing cost of equipment can prove to be an insurmountable obstacle reducing opportunities for those from deprived ethnic communities who may be convinced of the attraction of the game. Deprived of access to private schooling with few scholarships available, youngsters are denied the flexibility in the schooling system that a private education permits, and the state system denies, due to time pressures and scarce resources.

Furthermore, as Babb [22] (2015) points out, a British Labour Force survey reported that as early as 1998 among the black Caribbean population 48 per cent of men and 34 per et of women were in inter-ethnic relationships (Office for National Statistics 2001 \& 2006). This continuing trend demonstrates that within the growing numbers of people with mixed identities, the Caribbean heritage only represents a part. Thus the significance of West Indian cricket as a source of self-esteem is declining and Caribbean trans-generational solidarity has weakened. Consequently, the performance of the West Indies plays a lesser role in the continuing evolution of identity and parental upbringing within the diaspora.

Rather, it is the appeal of other sports and the degree to which great financial rewards are perceived as attainable, notably in football and in both codes of rugby that has lured a number of young Afro-Caribbean males. Interestingly, with the blending of communities, which has resulted in many Afro-Caribbean lads being directed to football by more recent African immigrants, the significance of heritage has declined as a determining factor in the construction of suitable role models. Whilst athletics and boxing had always proved a draw, these sports pale into significance as counter-attractions, despite the considerable success achieved in both by sportspeople of British Afro-Caribbean origin. The ultimate sporting distraction has been, and continues to be, football, which offers the chance to accumulate great riches in a short time period. This development and the progress made by Afro-Caribbean males in football is demonstrated by the fact that England's twenty-three man squad for the 2010 football World Cup in South Africa contained nine players of Caribbean descent, whereas between 1995 and 2010 only four players of Caribbean heritage made their test debuts for England.

Whereas the decline in interest in cricket has been evident (with the West Indies cricket's last achievement on British soil being its unexpected victory in the ICC Champions Trophy in 2004), athletics continues to remain very popular. This can be attributed to the achievements of Jamaican athletes (their pre-London Olympics training camp in Birmingham generated considerable enthusiasm) and also the success of British born athletes with Afro-Caribbean parentage at the London Olympics. The success of the Armitage brothers in Rugby Union, coupled with the emergence and recognition at international level of Jason Robinson, Courtenay Laws, Anthony Watson, Marland Yarde and Christian Wade have provided role models which cricket has lacked in recent times, with only Michael Carberry being able to effectively sustain this role. The 2017 tour party for the British and Lions matches in New Zealand contained more players of Afro-Caribbean heritage than has ever been the case, demonstrating once again the competition that cricket faces in recruiting young males to cricket.

The lack of young cricketers coming through the age groups is linked to the decline of Afro-Caribbean clubs, the paucity of opportunity to perform on good standard pitches, the decline of comprehensive school funding and facilities, the difficulty of breaking into county club academies, second eleven crickets and club cricket. For Carl Greenidge [23] "fewer opportunities exist to play. Clubs and counties are finding youngsters to play second eleven crickets and are rewarded handsomely for selecting players under the age of twenty-four, so why look elsewhere?" Equally critical in his view was the concern on some of the less positive changes in the game since his time as a player, more especially the fact that the counties as a rule tend to be far lazier in their efforts to seek out new talent compared to the days before the creation of the Haringey Cricket School.

The launch of the Haringey Cricket School under Reg Scarlett, a former West Indian Test cricketer, and Mickey Thompson, a much-respected British Afro-Caribbean coach, 
provided some opportunity for those in London to receive expert coaching and motivation to break into professional cricket or the higher levels of the recreational game. The record of achievement was astonishing and even though this pre-dated the launch of county academies, a remarkable number of high-level cricketers emerged. According to Williams [24] (2001), thirty three England players of Afro-Caribbean origin were playing in the County Championship in 1993. Although they were not all products of the Haringey initiative, this figure is twenty six more than the number of players of Afro-Caribbean ancestry playing at county level in 2015. This initiative was a landmark and is never likely to be repeated for financial reasons, irrespective of societal change and the continuing evolution of British Afro-Caribbean identity and its growing divorce from cricket. However, the esteem with which this venture is still regarded prompts regular efforts to relaunch the scheme.

In terms of nurturing Afro-Caribbean cricket much depended previously on the stalwarts of Caribbean clubs and many of these individuals have retired, lost interest, returned to the Caribbean or, in some cases, passed away. In many cases these individuals took their sons to watch matches that also fed an enthusiasm now increasingly lost. Their replacements are few, but, as with the successful Leeds Caribbean Club formed in 1948 and Leicester founded in 1957, some individuals in their late thirties have taken on responsibilities, realising that survival of their clubs is in their hands. As Tony Bowry [25], the Cultural Diversity Officer of the Yorkshire County Cricket Board noted, "In combining cricket with a dose of pragmatism, a broad range of extra-curricular activities, most notably musically based, we are slowly attracting new players to join. This is a key tool for the promotion of inter-racial contact and ethnic harmony". The earlier strength of West Indian clubs has lessened as they have become broader community hubs, spaces for social gatherings most notably in Leeds, Leicester and Stevenage and less exclusive in terms of their membership eligibility.

Now walking through parks in most urban settings young Afro-Caribbeans are not playing in improvised cricket matches, instead it is groups of mixed Asian lads who are keen to play in nearly any weather from March to late November, seeking to emulate the skills of Kohli, Malinga, Shakib Al Hassan and Yasir Shah. This scenario replicated across England and Wales and further emphasises the scope of the challenge that has not been helped by the decline in the fortune of the West Indies. These are lads who did not have to be coaxed into playing the game unlike their South Asian counterparts. Despite the fine words of New Labour regarding issues of social exclusion [26] the sums of money allocated to address the issue of generating increasing cricket participation levels were insufficient.

However, today's reality is different, defeating England at cricket and rejoicing in victory over the old master is no longer so important, as the diaspora has chosen to redefine its identity in different cultural creative and political terms.
Whereas cricket was formerly predominant as the mechanism for expressions of identity, it is no longer perceived as a vehicle for a fighting a corner and shoring up identity. However, neither does this equate with not needing cricket at all as a vehicle for accumulating life skills. The fortunes of the West Indies side are no longer significant in projecting the diaspora's identity and sense of nationality and this would not be dramatically be different if they were successful as the numbers of individuals with multiple personal connections to Caribbean history is declining. Consequently, the transmission of values and practices including cricket becomes ever more difficult and is becoming a daunting challenge to the community. Afro-Caribbean identity is increasingly shaped by the creative industries, music, fashion, literature and in a sporting context, football with the likes of Dwight Yorke, Chris Smalling, Rahim Sterling Marcus Rashford and the streetwise Ian Wright occupying the public consciousness in contrast to Viv Richards and his projection of post-colonialism and ideas grounded in black-power politics.

The 1999 carnival of cricket (The Cricket World Cup) did not attract a new generation of cricketers as hoped. England's early exit did not help and the Caribbean notion of carnival was hi-jacked by South Asian supporters who turned out in big numbers to support their national sides, displaying far more enthusiasm for the game and a keener understanding of how they might benefit as a consequence. The failure to capitalise on the hosting of the 1999 Cricket World Cup and the reluctance of the EWCB to really focus on Afro-Caribbean community, leaving the untapped talent to be discovered by small numbers of enthusiastic individuals' coaches and talent-spotters, served to undo the success achieved by those who strove so hard at Haringey.

\subsection{Caribbean Clubs}

The decline of Caribbean cricket clubs, chronicled in great detail by Williams [27] has further undermined the strength and untapped potential of Afro-Caribbean cricket. According to Steve Stephenson [28] a pillar of the Afro-Caribbean community and cricket enthusiast, this sharp decline has resulted in a fall from one hundred clubs in the 1970's to somewhere between twenty five and thirty today Babb [29].This reality denies the community of a sense of potential togetherness as well the opportunity for contests between different communities within the diaspora.

The case of the Sheffield Caribbean club (one of the most successful sporting clubs in the City with a strong reputation of producing talented players) is interesting in that in that it has chosen to take on a wider remit, taking on a broader view fighting against racism and overcoming struggles and disadvantages that had beset the city in the 1970s 1980s and 1990s opening up membership to Yemeni, Bangladeshi and Pakistani youth from the locality.

Clubs in Leeds and Leicester set a precedent seeing themselves as playing a wider ambassadorial role in the 
Community, forging links with West Indian communities and in the case of Leicester also opening up channels of communication with the city's African Caribbean Centre. In Stevenage the West Indies Sports and Social Club (in which cricket played a pivotal role) formed a hub for the surrounding Afro-Caribbean community, inspired by a climate of economic hardship, social and cultural change, involving itself in local politics and the marketing of the city. The Leicester based Mead Brooke Cavaliers was successful in boosting membership in a range of sports playing a broader role in the community despite its history as a long-established football club Campbell and Williams [30]

This decline is best viewed in the context of Malcolm's [31] remarks that:

“....The $19^{\text {th }}$ century construction of cricket as the quintessential English game, for just as the demand for participation in the game is mediated by the game's significance in colonial cultures, so the supply of opportunities is mediated by cultural ideologies of what it means to be English and what Englishness means."

Thus the key issue of how the game is defined within the media and cricket leagues the length and breadth of England and Wales remains central to an understanding of the limited opportunities that persist with respect to participation, coaching and extending the game in particular communities. With the Afro-Caribbean player pool being so limited, these issues have been magnified and have provided the narrative within which both the Afro- Caribbean community and its aspiring cricketers have had to contend.

\subsection{The Decline of the West Indies}

With the end of the West Indian era of global domination and the rapid sinking into mediocrity, those who had previously looked up to a team of heroes were bereft. Although both the England side and the first-class counties boasted record numbers of Afro-Caribbean and West Indian cricketers, none of its products approached the levels of skill and stardom that those who had represented the West Indies had possessed. However, despite the level of cultural investment, this success was something of an aberration along the lines of the Haringey miracle. The detachment from the radical notions of anti-imperialism, anti-colonialism as well as the fight for justice and democracy were no longer on cricket's agenda, with Vivian Richards representing the last West Indies captain linked to these causes.

In the United Kingdom, Richards' motivations were not generally understood within the cricketing fraternity and few identified with his ideals. With cricketers becoming more entrepreneurial and professional in marketing their skills, a good number have become "portfolio cricketers", not always valuing the notion of representing the West Indies or their birth island, but preferring to guarantee their long-term financial security and in some cases substantial personal wealth. The hand-over of the captaincy from Richards to Lara represented the detachment of the game from the historical discourse as Bateman \& Hill [32] a trend continued by Gayle whom Lara warmly endorsed as his successor.

With the loss of the Test series against Australia in the Caribbean (1994/5), twenty years of dominance came to an end. Coupled with a humiliating World Cup defeat to Kenya in 1996, the West Indies lost to the then strongest and weakest nations in international cricket. As Beckles [33] notes these defeats indicated that the recent guiding forces of West Indies were eroding, namely, professionalism and the supportive nationalist mentalities. These developments impacted on the Caribbean community who had long celebrated the successes of the West Indies team (with others having grown up with it) namely, sources of pride and inspiration were absent. Aside from the victory in the 2004 Champions Trophy the West Indies continued to perform poorly, whilst team selection and player availability often spawned disputes over money and priority notably for those acquiring the status of "Portfolio Cricketers" travelling the world to play in Twenty 20 tournaments. This impacted on the size of the West Indian audience at test venues who were dispirited by the performance of their team, the price of tickets, the need to book their tickets long in advance and the fact that the once famed entertainment stimulated by music, food, drink and musical instruments was barely possible with the EWCB regulations in place. The sense of an outing that was so familiar to the Caribbean crowd and beloved of many supporters in less corporate times had passed. The ground be it a test venue or a local cricket club was no longer the essential meeting place for the Caribbean resident.

These developments made the game even less attractive to the third and fourth generation of the West Indian diaspora. Cricket was no longer an elementary glue, whilst in sporting terms the devotion to football was intensifying with the growing increase in the numbers of Black British footballers and the numbers of top quality West Indians playing county cricket was dwindling because of their lack of availability due to the growth of Twenty 20 competitions in India, Sri Lanka, the West Indies (ironically in the middle of the English domestic season) and the now defunct Twenty 20 Champions League. Leicestershire's recruitment of Ramnaresh Sarwan was a rare exception in 2012, recruiting a major West Indies player for a whole season, whilst more recently Fidel Edwards and Tino Best have featured at both Hampshire and Yorkshire. As more money could be earned through short bursts of intense competition, than would be available from the slog of a long English season lasting nearly six months it is increasingly unlikely that the English counties will look to the Caribbean to recruit personnel.

This lack of West Indian visibility extended to the new format as the counties are not able to compete with the riches offered by Indian Premier League franchises since 2008 and so it has become more difficult for youngsters to watch their icons and they have only managed to catch fleeting glimpses of Chris Gayle, Darren Sammy Dwayne Bravo, Dwayne 
Smith, Kemar Roach, Shannon Gabriel and Kieron Pollard. This has increased disenchantment with the game and a thorough re-examination of the value of association with a failing team aside from its exploits in the global Twenty 20 format.

\subsection{New Initiatives}

A myriad of initiatives now exist with a view to re-igniting cricket within the Afro-Caribbean community. Among them, the most important are Chance to Shine, Cage Cricket, the Grass Roots Cricket Academy and the Taverners Cup. However, as the pool of individuals to choose from is small, the schemes in place also seek to attract young Asian males and white youngsters from deprived communities who lack access to the game.

Chance to Shine has managed to secure more attention for its work than other project. With the backing of a combination of major public figures, current and former players, the scheme is the one most familiar to the public having given two million children an opportunity to play cricket and develop some key life skills. However, ultimately its success can only be judged in terms of whether it is able to sustain interest and help to produce first class and future Test Match cricketers. Its objectives and work are laudable, yet twelve years on from its inception, the route into England team selection remains very limited and state schools remain unable to build on the taste for cricket given to many young boys and girls. This is not the fault of those providing the coaching and support, but the consequence of a two-fold dilemma. Firstly, having provided an entry point to the game, maintaining the interest of youngsters pulled in the direction of other sports and social distractions remains very difficult. Secondly, in seeking to meet this challenge there remains the political problem generated by the dispersal of limited resources from central government, leaving comprehensive schools with impossible decisions to be made regarding allocation of monies to competing priority areas.

Cage Cricket represents a very different approach thriving on an unorthodox approach, picking up youngsters who have been lost within the educational process. Thriving on notions of celebrity, the dominance of music (playing cricket whilst listening to music via headphones) and fashion, Cage Cricket seeks to offer a less conventional approach to sampling cricket. The approach of Cage Cricket, according to its co-founder Lawrence Prittipaul [34], is very much a response to this. "Get the fun done first. Attract them. Use graphics, appropriate language. Enjoy it and then there is a chance to move on. The key to our success is that we are online, not old school with a fifty-five year-old teaching you to play the front foot drive." Consequently, a fast moving six-a-side game has produced a positive response as it is deemed cool to play something quick, with a minimum of fuss and free of established tradition. Critically, it allows each person involved the chance to bat, bowl and field, thus giving all participants an all-round experience each time they participate. Although still a small-scale venture, Cage Cricket has managed to extend its activities to a number of towns and cities beyond London and with the support of Sir Ian Botham it obtains regular media attention.

Through Cricket for Change, the Jamaican Donovan Miller [35] (personal interview) has been offering outreach work including coaching sessions in state schools and a variety of cricket clubs in Greater London for some time, geared largely to disadvantaged adolescents. Proudly wearing his Royal Challengers Bangalore top courtesy of his link to Chris Gayle, Miller stressed the importance of mentoring cricketers, having received no guidance of this kind when he first arrived in England in 1996. However, it was the establishment of the Chris Gayle Academy and the personal involvement of Gayle himself that brought an astonishing response to a cricket day that Miller recently organised, bringing in for trials Afro-Caribbean males never previously seen at any of his coaching sessions. "Any young West Indian who plays cricket would want to be involved with Chris Gayle," he acknowledges. "We had seven decent cricketers turn up and they all will get into the academy. Maybe we need six more Chris Gayles".

As both the clearly overworked yet ever-cheery Carl Greenidge and Ricky Anderson Co-founders of Grass Roots Academy argue, the task is tough. They have found it very difficult to recruit Afro-Caribbean lads to their Academy, a non-profit organisation scheme a using cricket to enrich the academic and personal lives of under-privileged youths in the inner city of London via coaching and the teaching of life skills. The bulk of those interested and attending come from the Asian community, a point borne out by Mark Alleyne [36] when discussing the ethnic breakdown of applicants for MCC places. This reality is all the more hard-hitting for him as the impossibility of finding the right kind of club to compensate for the lack of school opportunities for his children has led to their drift towards football. Funding, according to Anderson, "is linked to participation numbers and consequently the search for finance to run schemes often take precedence over the specialist coaching work they are desperate to provide."

The Wisden City Cup (WCC) was designed as an initiative to bring cricket to inner-city communities where the popularity of the sport has manifestly declined, especially since the spike of interest when the Ashes were contested so dramatically in 2005. The objective was to give an opportunity to play on good club grounds to those who do not have the opportunity, and promote social cohesion along the way. The creation of the Wisden City Cup by the acclaimed journalist and long-standing campaigner for widening participation in cricket, Scyld Berry, has also offered Afro-Caribbean youngsters new opportunities to play. It will be interesting to see whether the link with the Lord's Taverners to boost further sponsorship will pay dividends along with the wider media exposure offered through its support from the EWCB, MCC and Wisden.

In 2013 the growth was maintained as the competition 
spread to Birmingham, Wolverhampton, Manchester and Bradford, in addition to the four existing cities. The players now have a competition within their own city, followed by the national knockout stages at the season's end, and the match against MCC Young Cricketers. The WCC has evolved into the first national knockout for inner-city cricketers and a talent identification competition for 16 to 22 year-olds. To reflect the support of the cricketing establishment, it has been re-named the ECB City Cup. However, as Berry [37] confirms (personal interview) the bulk of the participants in the competition are of Asian origin, again confirming the issues confronting those keen to rekindle the lust for cricket within the Afro-Caribbean community.

Ultimately, in seeking to ensure that the Caribbean cricketing heritage is not completely lost to the English and Welsh game, the EWCB does not have the power to radically change attitudes, though it may be able to respond to members of the Afro-Caribbean community once they are clear about the role cricket can play. Neither does the EWCB have the capacity to loosen the dominance of other sports that have redirected many Afro-Caribbean males from cricket, yet it also cannot afford to respond to the decline with mere rhetoric. The hope lies in the hands of current professionals such as Chris Jordan, Tymal Mills and Daniel Bell-Drummond to remind the community of the opportunities that the game has always offered and the rewards that are now available to individuals with differing cricketing pedigrees and origins. As Carberry advocates, few extra visits by some county and regional coaches into particularly deprived communities might pay dividends if those with interest and potential talent are communicated through a language with which they can identify and comprehend.

Undoubtedly some fine work is being undertaken by many dedicated cricket followers each of who have the longer-term future of the game at heart, such as the undoubted skills of coaches such as the greatly respected Tony Moody who is clearly able to connect with the constituency that he seeks to engage through the application of Jamaican street-games. However, in seeking to reverse a trend of growing disinclination towards the game, the creation of some form of co-ordinating body to maximise resources and compete effectively for scarce funds may well be the best course of action to take in a socio-economic climate where elite sport is so strongly favoured over the needs of grass-roots activity.

\section{Conclusions}

Although cricket no longer features prominently as part of an Afro-Caribbean barometer of contemporary self-worth and importance, it remains and retains a significant part of the social history of Caribbean people in the United Kingdom. As England now play a more attractive and dynamic style of cricket attracting a wider social and ethnic mix of fans, it is possible that this attacking style of play will spawn a new generation of interest especially in those sections of society that have become increasingly distant from a pastime that generates a range of skills as well as thrills.

The key to fostering and advancing cricket is to build on any initial interest captured by organising competitive fixtures, an absolute must in the eyes of Greenidge, Anderson and Alleyne. The loss of funds and facilities within the state school system will not be rapidly reversed and neither will the demise of West Indian clubs: however, this does not automatically imply the death of British Afro-Caribbean cricket. The game can and does remain relevant in its increasingly diverse forms to a community that has brought so much to it, but the drive towards rekindling interest will need a combination of local, national and global thinking as the international cricket community needs a vibrant West Indian team.

\section{REFERENCES}

[1] For more insight see D. Burdsey, Race, Ethnicity and Football: Routledge, London (2011)

[2] Interview with Carl Greenidge

[3] Discussed further by D. Malcolm Globalizing Cricket, Englishness, Empire and Identity, Bloomsbury, London (2013)

[4] See E. Weetch, The Carberry Question, The Nightwatchman, Vol 3, Autumn (2013) p87

[5] Interview with Mark Alleyne

[6] Mike Marqusee has written extensively regarding the failure of the cricketing authorities to acknowledge the potential of the diaspora communities

[7] A key strand of the thesis advanced by Weetch

[8] K. Spracklen offers a range of critically valuable definitions in his (2015) volume.

[9] See the discussion T. Fletcher, Cricket, Migration and Diasporic Community Identities in Global Studies in Culture and Power, Vol 22, No 2, (2015) pp 141-153

[10] This is best exemplified by T. Fletcher, in The Making of Cricket Cultures - Empire, Globalization and (post) Colonialism. Sport and Society, Vol 14, No 1, (Jan 2011), pp 17-36

[11] I. Macdonald \& S. Ugra in B. Carrington, \& I. Macdonald, Race, Sport and British Society, Routledge, London (ed. 2001)

[12] C. Searle, Pitch of Life: Writings on Cricket, Parrs Wood Press, Manchester (2001)

[13] Former MP and senior Government Minister questioned the support of diaspora communities for their adopted country

[14] Robert Henderson took the Tebbit assertion further with his 
racist slurs against non-UK born cricketers players representing England, see, It is in the Blood, Wisden Cricket Monthly (July 1995)

[15] M. Phillips, \& T. Phillips, Windrush. The Irresistable Rise of Multi-Racial Britain, Harper Collins, London (1999) pp 101-102

[16] Interview with Michael Carberry

[17] Interview with Tymal Mills

[18] Interview with Dean Wilson

[19] Interview with Alf Langley

[20] Interview with Mark Alleyne

[21] Interview with Lawrence Prittipaul,

[22] C. Babb They Gave The Crowd Plenty Fun, Nansib, Hertford, (2015)

[23] Interview with Carl Greenidge

[24] J. Williams, Cricket and Race, Berg, Oxford (2001)

[25] Interview with Tony Bowry

[26] Department of Culture Media and Sport. A Sporting Future for All (2001) p 39

[27] Chronicled in J. Williams, Cricket and Race, Berg, Oxford (2001)

[28] Steve Stephenson has a long history of encouraging Afro-Caribbean Cricket and hosting West Indian cricketers in the United Kingdom

[29] C. Babb explores this issue widely in his discourse on the changing nature of Afro-Caribbean identity.

[30] P. Campbell, \& J. Williams 'Race', politics and local football-continuity and change in the life of a British African-Caribbean local football club in Sport in Society Vol 18, No. 4, pp 425-439 (2015)

[31] See D. Malcolm Globalizing Cricket, Englishness, Empire and Identity, Bloomsbury, London (2013) p 21

[32] A. Bateman, \& J. Hill, The Cambridge Companion to Cricket, Cambridge University Press, Cambridge (2011)

[33] H. Beckles, The Development of West Indies Cricket, Vol 2, The Age of Globalisation, Pluto Press, London (1998)

[34] Interview with Lawrence Prittipaul

[35] Interview with Donovan Miller

[36] Interview with Mark Alleyne

[37] Interview with Scyld Berry

[38] C. Babb They Gave The Crowd Plenty Fun, Nansib, Hertford, (2015)

[39] A. Bateman, \& J. Hill, The Cambridge Companion to Cricket, Cambridge University Press, Cambridge (2011)

[40] H. Beckles, The Development of West Indies Cricket, Vol 2, The Age of Globalisation, Pluto Press, London (1998)

[41] D. Burdsey, British Asians and Football, Routledge, Abingdon 2007
[42] P. Campbell, \& J. Williams 'Race', politics and local football-continuity and change in the life of a British African-Caribbean local football club in Sport in Society Vol 18 , No. 4, pp 425-439 (2015)

[43] B. Carrington, \& I. Macdonald, Race, Sport and British Society, Routledge, London (ed. 2001)

[44] Department of Culture Media and Sport. A Sporting Future for All (2001)

[45] R. Henderson, It is in the Blood, Wisden Cricket Monthly (July 1995)

[46] D. Malcolm, Globalizing Cricket, Englishness, Empire and Identity ,Bloomsbury, London (2013)

[47] M. Marqusee, Anyone but England: Cricket, Race and Class, Verso, London (1998)

[48] M. Phillips, \& T. Phillips, Windrush. The Irresistible Rise of Multi-Racial Britain, Harper Collins, London (1999)

[49] Office for National Statistics online Ethnicity and IdentityCensus, p. 1

[50] Available at http://www.ons.gov.uk/peoplepopulationandcommunity $(2001,2006)$

[51] C. Searle, Pitch of Life: Writings on Cricket, Parrs Wood Press, Manchester (2001)

[52] K. Spracklen, Exploring Sports and Society- A Critical Introduction for Students, Palgrave, Basingstoke (2015)

[53] S. Wagg, Cricket and National Identity in the Postcolonial Age, Routledge, Abingdon (ed 2005)

[54] E. Weetch, The Carberry Question, The Nightwatchman, Vol 3, Autumn (2013)

[55] J. Williams, Cricket and Race, Berg, Oxford (2001)

[56] M. Alleyne, Former, MCC, Head Coach, Gloucestershire and England Cricketer, December $6^{\text {th }}, 2012$

[57] R. Anderson, Co-Founder, Grassroots Academy, June $20^{\text {th }}$, 2013

[58] S. Berry, Cricket Correspondent, Sunday Telgraph, June $8^{\text {th }}$, 2017

[59] T. Bowry, Cultural Diversity Officer Yorkshire, County Cricket Board, July 9 ${ }^{\text {th }}, 2013$

[60] M. Carberry, Hampshire and England Cricketer, February $28^{\text {th }}$, 2014

[61] C. Greenidge, Co-Founder, Grassroots Academy, February $20^{\text {th }}, 2013$

[62] A. Langley, Former President, League Cricket Conference, February $5^{\text {th }}, 2014$

[63] D. Miller, Cricket, Coach, Cricket for Change, June 19 ${ }^{\text {th }}, 2013$

[64] T. Mills, Sussex and England Cricketer, December $6^{\text {th }}, 2013$

[65] L. Prittipaul, Co-Founder, Cage Cricket, March $5^{\text {th }}, 2013$

[66] D. Wilson, Cricket, Correspondent, The Daily Mirror, July $20^{\text {th }}, 2013$ 